\title{
El principio de causalidad y la ocurrencia esencial
}

The Principle of Causality and the Essential Occurrence

RAFAel CoRAzóN

Profesor de enseñanza secundaria rafcorazon@yahoo.es
RECIBIDO: ? DE ? DE 201?

VERSIÓN DEFINITIVA: ? DE ? DE 201? DOI: $10.15581 / 013.19 .83-110$
Resumen: El principio de causalidad es la vigencia del principio de Identidad respecto del principio de no contradicción, impidiendo, por ello, que se "maclen", o sea, que se incluyan uno en otro. Por eso mismo, es también la demostración de la existencia de Dios. Pero de él depende también que el acto de ser creado admita, como análisis pasivo, la esencia extramental, la cual, por distinguirse realmente del ser, no puede decirse propiamente que existe, sino que "ocurre".

Palabras clave: Primeros principios, causalidad, esencia, existencia, "ocurrencia".
Abstract: The principle of causality is the applicability of the principle of identity with respect to the principle of non-contradiction, avoiding, therefore, that a macle occurs, that is, to be included in one another. For this reason, it is also the demonstration of God's existence. But it also depends on him that the act of being created admits, as passive analysis, the extramental essence, which, by really distinguish itself from being, it can not properly be said to exist, but that "it's happening".

Keywords: Main Principles, Causality, Essence, Existence, "It's Happening". 


\section{EL PRINCIPIO DE CAUSALIDAD COMO PRIMER PRINCIPIO}

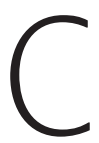

uando Polo expone los primeros principios, siempre se refiere al ser: no son principios lógicos sino reales y, además, son actos de ser. Este planteamiento es novedoso en la historia de la filosofía, pues, tanto en el pensamiento clásico como en el moderno, los primeros principios son principios lógicos y, en algunos autores, también principios reales, pero no como actos sino como leyes que rigen el ser o las formas.

Éste es el caso del principio de contradicción en Aristóteles, y también en santo Tomás. Aristóteles, al definir la noción de "principio", en la Metafísica, expone hasta seis significados del término, y resume todos esos sentidos del siguiente modo: "lo común a todo tipo de principios es ser lo primero a partir de lo cual algo es, o se produce, o se conoce. $\mathrm{Y}$ de ellos, unos son inmanentes y otros son extrínsecos, y de ahí que principio sean la naturaleza y el elemento, el pensamiento y la voluntad, la esencia y el para-que"." En cambio, al comienzo del libro IV "principio" se asimila a causa ${ }^{2}$, aunque, al formular y explicar sus características, el primer principio recibe también el nombre de "axioma" y tiene un sentido exclusivamente lógico. El comentario tomista correspondiente sigue fielmente a Aristóteles y, por consiguiente, se ciñe a su sentido meramente lógico.

Para referirse a principios 'reales' estos autores clásicos prefieren usar el término 'causa', pues, como dice santo Tomás, “'causa' suele comportar la idea de influjo; 'principio' comporta la idea de orden y prioridad en éste (cfr. AQUINO, 751)"

Otra novedad de la metafísica de Polo es que, para él, los primeros principios son tres, cada uno de los cuales es principio primero por derecho propio, hasta el punto que si alguno se "macla" o se incluye en otro, deja de conocerse como principio, con la consecuencia añadida de que el tercero en discordia deja también de ser primer principio ${ }^{4}$.

${ }^{1}$ ARISTÓTELES, Metafísica, V (Ä), 1, 1012b 33-1013a 23.

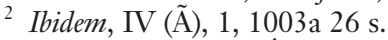

3 T. CALVO MARTÍNEZ, en ARISTÓTELES, Metafísica, Gredos, Madrid, 1994, 206, nt. 4. La cita del comentario de santo Tomás a la Metafísica sigue la edición Marietti, Turín, 1977. "La metafísica prematura confunde las causas con los primeros principios". L. POLO, Curso de teoría del conocimiento, IV, Eunsa, Pamplona, 22004, 320.

${ }^{4}$ No es infrecuente afirmar que sólo puede haber un único primer principio pues, si es primero no puede haber un segundo que también sea primero, ya que sería una contradicción. Naturalmente, se refiere a principios lógicos. Cfr. E. ALARCÓN, voz "Primeros principios", en A. L. GONZÁLEZ (Ed.), Diccionario de filosofía, Eunsa, Pamplona, 2010, 936-938. 
Para comprender cómo entiende Polo los primeros principios de la metafísica, distintos de los axiomas de la teoría del conocimiento y de los principios lógicos, hay que tener en cuenta el "método" para alcanzarlos, ya que dichos principios son su "tema". Por eso es válida la siguiente descripción: "lo diferencial de la metafísica respecto de los ámbitos del pensamiento y de la conducta humanos se refiere a esta prioridad de la presencia [mental] en dichos ámbitos. La metafísica se destaca del pensamiento y de la cultura porque se ocupa del ser, y el ser es otra prioridad distinta, precisamente aquella que no está ya dada de antemano: la prioridad absoluta o enteramente independiente, a la que llamaremos prioridad fundamental o fundamento, sea estrictamente unitaria o plural"s. O, de un modo más directo, "la metafísica se distingue del pensar y del hacer humanos por cuanto se ocupa del ser en su irrestricta prioridad".

En esta breve exposición puede apreciarse la diferencia fundamental entre el modo de entender la metafísica de Polo y lo que, históricamente, se ha entendido por tal: la metafísica no es, para Polo, una "ciencia", un estudio o un conocimiento cierto por causas -como suele definirse-, ni la ciencia del ente en cuanto ente, sino la "advertencia" de los primeros principios, o sea, del ser, sin necesidad de "teorías" que, más que explicar qué es el ser, lo sustituirían". Por eso "los primeros principios han de entenderse como actos de ser". Los principios son reales, son actos, y no pueden "pensarse" -objetivarse- sino sólo "advertirse" abandonando el pensar objetivo, el límite mental.

Polo sostiene, además, que los primeros principios son tres: el de no contradicción, el de Identidad y el de causalidad. El primer principio no contradictorio es el acto de ser del universo, del mundo físico; el principio de Identidad es Dios; pero, ¿qué acto de ser equivale al principio de causalidad? Desde El Ser, publicado en 1965, Polo trató sobre este tema numerosas veces, especialmente en Nominalismo, idealismo y realismo, publicado en 1997. Treinta y dos años separan un libro del otro y, sin embargo, según relata I. Falgueras, "hace relativamente poco -aunque no puedo precisar la fecha, estando él ya enfermo- que en conversación privada me dijo D. Leonardo Polo que una de

5 J. A. GARCÍA GONZÁLEZ, Principio sin continuación, Universidad de Málaga, 1998, 77.

${ }^{6}$ Ibidem, 78.

${ }^{7}$ Sobre el objeto de la metafísica en Polo, cfr. R. CORAZÓN, La idea ente. El objeto de la metafísica en la filosofía de Leonardo Polo, Cuadernos de pensamiento español, Servicio de Publicaciones de la Universidad de Navarra, Pamplona, 2014.

8 L. POLO, Nominalismo, idealismo y realismo, Eunsa, Pamplona, 1997, 253. 
las cosas que se le habían resistido (como filósofo) era la descripción real del principio de causalidad como primer principio".

El problema que plantea el principio de causalidad, en breves palabras, es que, por un lado, es un acto de ser y, por otro, Polo no admite más actos de ser que la persistencia o acto de ser del universo, Dios y el acto de ser personal creado o co-ser. ¿Qué se advierte cuando se advierte el principio de causalidad? Quizás las siguientes reflexiones sobre los textos de Polo y algunos de sus discípulos puedan servir para avanzar en la descripción de este principio.

Adelantando ya la conclusión, lo que aquí se quiere explicar es que el principio de no contradicción es el ser del universo en cuanto acto primero inidéntico o que no culmina, y, en cambio, el principio de causalidad es el acto de ser del universo en cuanto creado; pero teniendo en cuenta que la persistencia se advierte como primera tan sólo si a la par se advierte como creada, o dicho de otro modo, su distinción respecto de la nada se advierte tan sólo si se advierte su distinción respecto de Dios.

Un primer texto nos servirá para situarnos ante el problema: "lo primero, sin más, es ser. Los primeros principios no son manifestaciones o aspectos del ser, sino la intelección del ser en tanto que primero. Según la intelección, cabe ser como no contradicción, como causa y como identidad; o también: inteligir la no contradicción como ser, la causalidad como ser y la identidad como ser"10. Según esto, la conclusión precipitada es que se trata de tres seres, pero, sin embargo, el "tercer ser" no aparece nunca en las obras de Polo cuando trata de la primera dimensión del abandono del límite mental, o sea, del ser principial o como principio.

Si hubiera que ordenar la advertencia de los primeros principios, habría que decir que primero se advierte la no contradicción, que Polo describe "como el principiar primero -suelo hablar de comienzo- que ni cesa ni es seguido... Si no contradicción significa criatura, y criatura comenzar a ser, comenzar a ser es no contradictorio en tanto que no cesa y en tanto que no es seguido... No contradicción significa persistir y, así, acto de ser creado: comenzar sin ser

\footnotetext{
9 I. FALGUERAS, "El principio de causalidad en la metafísica de hoy", en Miscelanea Poliana, 2013 (4-1), 14. Polo reconocía que era difícil expresar el carácter peculiar de ese primer principio. Alguna vez manifestó que las fórmulas más precisas que había logrado, escritas en los márgenes de El ser con miras a la corrección en una edición ulterior, quedaron recortadas y, por eso, ilegibles, cuando encuadernaron sus libros, y que no había podido recuperar esa precisión.

${ }^{10}$ L. POLO, Nominalismo, 243-244.
} 
seguido ni cesar es el acto de ser creado como primer principio" 11 . Advertir el ser no contradictorio es advertirlo como creado, y ello porque "comienza", sin que dicho comienzo sea absoluto; por último, "el acto de ser de Dios no es no contradictorio porque no tiene nada que ver con el comenzar; es Increado" ${ }^{12}$.

Es notable -porque es el primero en sentarlo- que Polo afirme que el acto de ser que significa persistir, se advierte antes como ser creado que como ser primero, es decir, que su distinción respecto de la nada -como ser- se sigue de su dependencia respecto de Dios -como criatura-: "el ser creado se distingue radicalmente de la nada. En este sentido se dice que es extra nibilum. Pero, a su vez, es característico del ser creado ser ad extra respecto del Creador, de tal forma que la distinción que expresa el extra nibilum es inferior a la que expresa el ad extra... Insisto, el ser creado se distingue menos de la nada que de Dios"13. Más aún, no se podría advertir la persistencia si no se advirtiera como criatura, hasta el punto de que "la distinción de ser y nada cede ante la distinción de la criatura y Dios. Precisamente por eso, la criatura no se opone a la nada -como si la nada fuera diferente de ella-, sino que sigue siendo como persistir o bien como co-existir" ${ }^{\prime 14}$.

Este último texto es fundamental para comprender qué se advierte y cómo en el principio de causalidad. Polo afirma que la criatura, por distinguirse de Dios más que de la nada, persiste o, de otro modo, se advierte la persistencia si no se "piensa" a la criatura como dotada de consistencia o de una cierta suficiencia: "la suposición se introduce, sin remedio, si la persistencia se desliga de la consideración de la causalidad. La investigación acerca de la persistencia incluye, como penetración en la máxima amplitud, la demostración de la existencia de Dios" ${ }^{15}$.

Pero dicha demostración no es un razonamiento o un argumento, sino el principio de causalidad. "La demostración de la existencia de Dios es una denotación causal de la advertencia de la existencia"16 y la razón es que "antes de entender la referencia de acuerdo con la noción de causa, el tema del ser está amenazado por la anticipación, por la tendencia a quererlo cobrar como un resultado asentado y seguro... Sólo en la consideración de la causalidad se abre

\footnotetext{
11 Ibidem, 246.

12 Ibidem, 247.

${ }^{13}$ L. POLO, Antropología trascendental, I, Eunsa, Pamplona, ${ }^{22} 2003$, 130-131.

${ }^{14}$ Ibidem, 129.

15 L. POLO, El ser, Universidad de Navarra, Pamplona, 1966, 230.

${ }^{16}$ Ibidem.
} 
a la identidad. Conviene, por tanto, insistir en el carácter inconcluso de la advertencia de la existencia extramental”" ${ }^{\prime 7}$.

Advertir el ser es advertir que no culmina, que es inidéntico; y eso es precisamente advertirlo como criatura. El ser del universo, la persistencia, es principio incesante que no es seguido; en cuanto que no es seguido se advierte su inidentidad, su carácter de criatura. Las dos advertencias son en realidad una sola: el ser principial, pero manifestando dos características distintas aunque dependientes una de otra. Polo lo expresa así: "el carácter de criatura no puede ser algo añadido a la criatura; ha de ser la criatura en tanto que no consumada en sí. De lo contrario no se advierte el carácter de primer principio de la causalidad... Por eso digo que la causalidad es un primer principio". O sin más rodeos: "en cuanto que la criatura demuestra la existencia de Dios, comporta el primer principio de causalidad en tanto que este principio equivale a la causa causada, es decir, entendida como no culminación de la criatura... Esa dependencia es el primer principio de causalidad: no 'otra' criatura, sino el respecto real, primero como acto de la criatura con Dios -la vigencia entre sí de la no contradicción y la identidad-""18.

Hay aquí una dificultad no fácil de evitar a la hora de expresar cómo la persistencia demuestra la existencia de Dios. La demostración es la no culminación, y se debe al comienzo, que es lo que impide la culminación. Para advertir esto pueden ser relevantes otros textos que, si se leen sin especial atención, parecen desmentir lo dicho: "si la persistencia no comportara esa referencia [al Origen], sería ultimada; y si fuese ultimada, ella misma sería contradictoria -cesaría, sería seguida-. Pero no puede serlo" ${ }^{19}$. La persistencia, sin referencia al Origen, en realidad, no sería. Por eso, la creación "se puede llamar relación [como lo hace santo Tomás, por ejemplo]; no en cuanto añadida, o como un accidente, sino como respecto al primer principio de identidad: como estricta dependencia respecto de él, propia de aquello que no puede ser consumado" ${ }^{20}$.

17 Ibidem, 231.

${ }^{18}$ L. POLO, Nominalismo, 254.

${ }^{19}$ Ibidem, 251.

${ }^{20}$ Ibidem, 254. "Causa causada no es causa producida, o causa pasiva, sino causa que depende en cuanto tal. Aquello de que la causa depende es la noción de Altísimo. La dependencia causal, es decir, la misma actividad de la causa, es intrínseca a la causa, por lo cual es inútil entender a esta última, ontológicamente, como producida... La causalidad es la dependencia. La dependencia es la referencia. La referencia es el enlace, de ninguna manera una relación cuyos términos estén dados. Sólo si se entiende la referencia en el sentido de enlace causal y no en el sentido de relación, puede admitirse que la analítica de la actividad creada sea pasiva y tenga el sentido de congruencia esencia (ocurrencia)". L. POLO, El ser, 241. 
La imposibilidad de consumación se encuentra no tanto en el "no ser seguido" -eso es una consecuencia necesaria-, sino en el comienzo, pues carece de sentido un comienzo absoluto, un comienzo que se consumase al comenzar, que no fuera seguido, o sea, que ni llegara a comenzar ${ }^{21}$. Por eso, la creación ex nibilo "destaca la proximidad a la nada de la esencia extramental como potencia entendida como antes temporal. La persistencia, es decir, el comienzo que ni cesa ni es seguido es indicado por el después temporal. Por tanto, la ocurrencia de la esencia no sigue a la persistencia ni es para ella ninguna culminación, sino un análisis que como antes indica la carencia de identidad del comienzo creado" ${ }^{\prime 2}$. Si el comienzo no es, ni puede ser, absoluto, el ser creado no puede ser idéntico. El ser creado no puede ser más que persistencia sin culminación: comienzo incesante, y por eso inidentidad no consumada; pero "comienzo" porque no es la Identidad, e incesante o que no culmina porque es no contradictorio.

El comienzo carece de antecedente ${ }^{23}$. Dar el ser es crear de la nada, pero, por eso mismo, en estricta dependencia del Creador, dependencia no temporal sino en el mismo ser creado; no en su "constitución”, en su fieri, sino en su comienzo persistente o incesante ${ }^{24}$.

En definitiva, el principio de causalidad es, en directo y sin necesidad de razonamientos, la demostración de la existencia de Dios a partir de la criatura: "los primeros principios han de entenderse como actos de ser. Y también la causalidad trascendental se puede llamar acto de ser: es otro primer principio. Con todo, el principio de causalidad trascendental no es 'otro' acto de ser

${ }^{21}$ Cfr. F. HAYA, "La superación del tiempo (III): los sentidos del comienzo", en Studia Poliana, 8 (2006), 157.

22 L. POLO, Antropología, I, 128, nt. 134. Otra descripción del principio de no contradicción, a la que aquí se refiere Polo, es la siguiente: "la realidad de la secuencia del antes y el después". En Polo "antes" indica unas veces la esencia extramental y otras la causa material; pero no hay contradicción entre ambos usos pues la esencia física no puede darse sin la causa material. El siguiente texto puede servir para acabar con posibles confusiones: "la presencia exime de la principiación causal, que ocurre antes. De este modo, la presencia suple al después, y, en este sentido, puede conocer el antes al despojarse de lo que tiene de superior a él. La concurrencia causal completa corresponde a la esencia del universo; el después a su acto de ser. Para conocer el acto de ser es preciso el abandono completo de la presencia”. L. POLO, Cuso de teoría, IV, 127, nt. 34.

23 "El movimiento no es el paso a un término o estado, sino el mismo carácter de comienzo y de primero del ser. Sólo advirtiendo el carácter de primero se entiende la noción de contingencia. La contingencia no puede cifrarse en la circunstancia de que la criatura pueda comenzar o no. La criatura causal equivale al comienzo: he aquí su contingencia”. L. POLO, El ser, 276.

24 "La existencia creada debe asumir el carácter de comienzo. El sentido de la distinción con el Ser originario no es otro que éste". L. POLO, El ser, 277. 
(eso implica suponerlo, cosificar el acto de ser), sino precisamente acto no maclado: el acto de ser de la criatura no es idéntico, y, como no culmina, es causa como causa causada". El principio de causalidad "es el respecto de un principio a otro, pero sin macla" ${ }^{25}$. El modo de no maclar $^{26}$ la Identidad y la persistencia es, pues, la advertencia del principio de causalidad; así se evita el monismo panteísta, y también el emanacionismo y la concepción de la creación como causación, lo que conllevaría la idea de participación y de degradación ${ }^{27}$.

\section{LA CAUSALIDAD TRASCENDENTAL}

Resulta difícil expresar el carácter peculiar del primer principio de causalidad o causalidad trascendental, puesto que en lugar de un acto de ser creado distinto de otros, es cierto vínculo o enlace real, no meramente una conexión o nexo de índole lógica, entre el acto de ser extramental o extraintelectual y el Origen, a saber, la dependencia del ser extramental respecto del Origen, que se advierte en el persistir. Por decirlo así, advertir el persistir equivale a advertir su dependencia respecto del Origen, que se llama causalidad porque el acto de ser que depende es causal, principial, como lo muestra su análisis real según distintas concausalidades o co-principiaciones.

Teniendo en cuenta estas precisiones, Polo acuña la expresión "causa causada" para referirse a la criatura: lo creado es la causa, que es causada por ser creada (aquí causada no indica "efecto", por eso Polo no habla de causa efectuada o de Dios como Causa Primera); y es "causa" indicando el ser, su inidentidad. Inidentidad equivale a persistencia, la cual "se distingue realmente de la esencia por ser respectiva al Origen como causa causada; por eso, admite esencia como analítica de la persistencia". De ahí que "el beneficio del principio de causalidad -sin macla- para la persistencia es la analítica causal... Sin la causalidad trascendental no ocurriría la predicamental”28. O sea, la esen-

${ }^{25}$ L. POLO, Nominalismo, 253.

${ }^{26}$ El verbo "maclar" no existe en castellano; sí existe el sustantivo "macla". Polo lo usa también como verbo para significar la inclusión de un primer principio en otro llevada a cabo tanto por la filosofía clásica como por la moderna.

27 "Causa causada" equivale a causa creada; en cambio, "la idea de causa incausada es inadmisible porque comporta la idea de espontaneidad, y la degradación ontológica”. L. POLO, Nominalismo, 248.

${ }^{28}$ Ibidem. 
cia depende del acto de ser, el cual no es, por eso, el acto de la esencia, y depende -no se identifica con él- porque es "causado".

Queda claro que ninguna criatura carece ni puede carecer de esencia, ya que la esencia es la consecuencia de la inidentidad del acto -de la realidad de la secuencia del antes y el después-, y, además, la esencia es potencial; no es "otro" acto que se añada al acto de ser creado, pues no existe un esse essentiae. La esencia no podría "ocurrir" sin la secuencia del antes y el después. El antes equivale a potencialidad ${ }^{29}$.

Si ser creado es no ser idéntico, sólo puede ser un "comienzo", que implica un "retraso", un no llegar a ser lo que es, no culminar y, por tanto, ser la realidad de una secuencia en la que el "antes" acompaña al comienzo impidiendo que el "después" culmine: "la distinción real de antes y después no es una separación o una distancia... Que el antes no es el después debe entenderse en el sentido de que el movimiento no es uno según la idea de identidad" ${ }^{30}$.

Si la criatura fuera acto puro, su esencia sería idéntica a su ser, y tan trascendental como él. Pero por ser un "comienzo" carente de anticipación, admite un análisis pasivo, una analítica, no de su actividad sino de su inidentidad. La esencia en cuanto tal, por tanto, no indica finitud ni limitación (no lo indica en Dios); pero en la criatura el comienzo incesante exige que sea finita y limitada. Por eso el principio de causalidad indica que la causa -el primer principio- es causada, es decir, que por ser un principio que comienza incesantemente, depende -sin macla- de la Identidad Originaria.

La esencia de la criatura es, por eso, potencial: "potencia significa para el acto carencia de sí mismo. La consideración de la potencia como tal impide toda comparación de la potencia con el acto. Paralelamente, hay que desechar la idea de relación entre acto y potencia. Ahora bien, esto no quiere decir que potencia signifique nada ni que esté 'aislada' del acto... La potencia no tiene una positividad propia de que venga dotada por el acto. Su admisión no es un debilitamiento del acto, obligado a alguna tarea, sino precisamente la advertencia del acto. La admisión de la potencia no es determinación alguna, sino la persisten-

\footnotetext{
29 "El antes temporal no puede ser asociado a la referencia, pero es absolutamente preciso no desterrarlo por completo, por cuanto solamente distinguiéndolo de la existencia es posible interpretar a ésta como referencia causal... Ser creado es el comienzo cuya persistencia no puede decirse distinta de él, no porque el comienzo la contenga, siquiera implícitamente, sino porque para comenzar a ser es preciso no anticiparse al después. El movimiento no es un cambio o una relación consigo porque el comienzo no se anticipa". L. POLO, El ser, 267 y 269.

${ }^{30}$ L. POLO, El ser, 270.
} 
cia activa" ${ }^{31}$. Otro texto más: "la advertencia del acto no se logra a partir de la potencia, sino como admisión de la potencia"32.

No culminar no quiere decir proseguir indefinidamente, sino depender: "su no consumación no puede entenderse como continuación indefinida, sino como vigencia respecto del Origen. Dicho respecto es la causa causada, que por ello se intelige como otro primer principio" ${ }^{33}$.

La persistencia es causa causada porque la dependencia equivale a la creación; es causa porque, al ser inidéntica, es la realidad de la secuencia del antes y el después, es un comienzo incesante que, por no cesar de comenzar (por no dejar atrás el comienzo), debe distribuir su eficiencia de modo que nunca puede ser definitivo.

Por eso el principio de causalidad equivale al ser creado en cuanto dependiente pero, a la vez, en cuanto sujeto a análisis, aunque análisis pasivo, pues lo que con el análisis se "halla" o "encuentra" son causas segundas -dependientes del acto de ser- que sólo causan en concausalidad: o sea, son coprincipios primeros, y por ello no trascendentales sino categoriales. La esencia es consecuencia de la inidentidad, su manifestación.

La inidentidad implica la "ocurrencia causal”, una nueva principiación que depende del acto de ser, que no se cumple nunca plenamente, o sea, que nunca alcanza a ser acto ni -con mayor motivo- a ser actual. Por eso de la esencia Polo no dice que "es" sino que "ocurre" (el ser es la persistencia) pues, "carece de positividad propia", pero cuya admisión es "precisamente la advertencia del acto".

El acto de ser se "advierte"; la esencia extramental, por el contrario, se "halla" o "encuentra". No puede "advertirse" porque no es acto sino potencia, pero debe "admitirse" porque el acto es inidéntico y la falta de identidad equivale a "comenzar", o sea, a eficiencia distribuida y nunca consumada: "su admisión es la advertencia de la persistencia del acto" ${ }^{34}$.

\section{LA CAUSALIDAD PREDICAMENTAL}

Dice Polo que el beneficio, para la persistencia, de la causalidad trascendental, es la causalidad predicamental; sin aquélla no sería posible la segunda.

\footnotetext{
L. POLO, El ser, 152.

32 Ibidem, 148.

${ }^{33}$ Ibidem, 251, nt. 40.

${ }^{34}$ L. POLO, El ser, 149.
} 
Además, la causalidad predicamental equivale a la ocurrencia esencial, potencial y, por eso, pasiva.

Estas descripciones son, de entrada, desconcertantes, porque la noción de potencia aristotélica no coincide con ella; más aún, es muy distinta, y Polo no la considera válida. Pensar que la potencia es un "principio de movimiento", o sea, que está llamada, por su misma naturaleza, a dejar de ser potencia y actualizarse, no es coherente. La potencia no es una especie de "casi" ser, una expectativa respecto del acto. Y menos aún cabe hablar de un "acto" de la potencia, como sucede en la definición aristotélica del movimiento: acto de la potencia o acto de lo que está en potencia en cuanto que está en potencia.

Polo siempre describe a la esencia como la analítica pasiva del acto de ser creado, de tal modo que, si se parte de la idea aristotélica de potencia, resulta ininteligible. "El acto no es un término por alcanzar, ni cabe admitir una tensión de la potencia por la cual ésta alcance a 'dejar de ser' como tal potencia”35. Otra frase desconcertante pero que nos puede servir para comprender lo que Polo entiende por potencia: "no cabe admitir un paso desde la potencia hasta el acto -bien como proceso tendido entre ambos, bien como transformaciónporque el movimiento y el acto se equiparan con el comienzo" ${ }^{\text {36 }}$.

¿Qué significa entonces "análisis pasivo" del acto de ser? Para comprenderlo hay que partir de lo siguiente: el acto de ser creado es no contradictorio pero no es idéntico. Hacer compatible ambas características es lo que da lugar a la analítica causal. Pero para exponer con mayor claridad cómo tiene lugar este análisis -real, no lógico- es mejor tomar como punto de partida otras descripciones del principio de no contradicción; en concreto, las siguientes: "comienzo que ni cesa ni es seguido" y "realidad de la secuencia del antes y el después".

La criatura comienza y en eso, entre otras muchas cosas, se distingue de la Identidad. Y además comienza sin antecedente, sin que quepa admitir algo previo; en concreto, sin admitir la nada y, menos aún, la Identidad como Causa Primera.

El problema inmediato es comprender qué significa "comienzo" en estas condiciones. Antes de entrar en el tema es preciso evitar algunos posibles equívocos. En concreto, "de la actividad existencial no resulta la esencia. La pretensión de considerar la esencia desde la existencia es olvidarse de que la

${ }^{35}$ L. POLO, El ser, 271.
36 Ibidem, 272. 
existencia es una referencia a la identidad creadora" ${ }^{37}$. Si la " "existencia que pone' no tiene sentido", es decir, si la esencia no es "causada" por el ser, "el análisis de la causa no puede entenderse activamente, ya que un pretendido análisis activo determinaría a la existencia como analizada. Pero el análisis no puede ser realmente idéntico a lo analizado... La no inclusión de la existencia sólo puede entenderse como distinción de valores causales" ${ }^{\prime 38}$.

Otro equívoco -ya señalado por Polo en las citas anteriores- sería pretender "hallar" la esencia mediante el análisis de la existencia; Polo lo ha expresado claramente así: "de la actividad existencial no resulta la esencia. La pretensión de considerar la esencia desde la existencia es olvidarse de que la existencia es una referencia a la identidad creadora". Esto no quiere decir que ser y esencia estén tan distantes que no tengan nada que ver entre sí, sino que el hallazgo de la esencia no puede obtenerse en la primera dimensión del abandono del límite mental. Como ya se ha dicho, en esta dimensión del abandono, la esencia se "admite", es decir, se admite que la persistencia se analiza en co-principios.

Para llevar a cabo el análisis del acto de ser es preciso partir del conocimiento objetivo. Polo llama al abstracto "lo vasto", porque no es simple sino que guarda implícitos que deben explicitarse mediante las operaciones racionales de concebir, juzgar y fundar. En concreto, en las dos primeras se explicitan las causas predicamentales, aunque dicha explicitación no es completa hasta el juicio. La explicitación no requiere el abandono del límite mental del mismo modo que la advertencia de los primeros principios, sino la pugna de la presencia mental con las causas predicamentales. Sería un error, por tanto, pretender hallar la esencia del universo analizando en directo el acto de ser; a lo más se seguiría un análisis lógico o mental, nunca un análisis real y pasivo del principio de no contradicción. Pero una vez halladas las causas predicamentales y las diversas concausalidades que "ocurren" en el universo, sí es posible atender a su relación con el acto de ser, puesto que la esencia "depende" de él.

Ahora es posible responder a la pregunta sobre el comienzo. De entrada "comienzo" significa "retraso", porque no culmina -ni puede culminar-, ya que culminar sería, por una parte, contradictorio, y por otra, tampoco se asimilaría a la Identidad, que no comienza. Un comienzo que culminara al comenzar ni siquiera comenzaría: no se distinguiría, ni siquiera mentalmente, de la nada.

${ }^{37}$ L. POLO, "La cuestión de la esencia extramental", en Anuario filosófico, 4 (1971), 299-300.

${ }^{38}$ Ibidem, 300. 
Comenzar, en la criatura, significa "comienzo incesante" o "incesante comenzar"; no en el sentido de un "amago" que no llega a cumplirse nunca, sino en el sentido de un "retraso" que impide que el comienzo culmine. Por eso, "el conjuntar es el comenzar... La causa conjuntiva es el carácter causal de la conjunción: la conjunción como causa... Si el antes es incesante, la conjunción es continua" ${ }^{39}$. Comenzar es conjuntar la causa material y la final, el retraso que, en principio, impide empezar, y el no ser seguido, el no culminar sin por ello no depender, o sea, impedir que el comienzo quede abortado. Si la persistencia no culmina, ha de "retrasarse" continuamente, de modo que no logre su fin, su culminación; pero el modo de "ocurrir" dicho retraso es mediante la concausalidad materia-fin, que sólo puede darse (ocurrir) si la causa eficiente conserva la diferencia entre ambas. Por eso dice Polo: "por cuanto la operación tiene un valor unitario en el que se cifra la conservación de la diferencia como un nuevo sentido de la causalidad, que llamamos eficiencia, es a ella a la que más directamente corresponde la ocurrencia esencial”"

El comienzo, aunque incesante, no culmina, no puede "acabar" o llegar a plenitud. Por eso, si se analiza el acto de ser, se "halla" un sentido causal que "retrasa" la secuencia impidiendo que el después culmine. Pues bien, "el carácter causal de la materia se cifra estrictamente en impedir el despliegue de la finalidad" ${ }^{41}$.

La causa final no puede faltar porque si el acto es susceptible de análisis (ya que nunca coincidirá consigo mismo), "la referencia causal [de unas causas a otras, o sea, las concausalidades] es uno de los sentidos de la causalidad al que llamaré causa final"42.

No sería adecuado preguntar qué es lo que comienza o qué fin persigue aquello que comienza. No debe "suponerse" un sujeto que comienza porque, en ese caso habría que dar razón del sujeto, explicar qué o quién es y por qué existe. Precisamente lo que se está tratando de describir es el "comienzo" sin antecedente previo, o sea, sin sujeto. Y la razón es que "comenzar" es pura ganancia, ser, acto. Si el acto se "supone" ya dado, no habría necesidad de advertirlo -se da por conocido-, ni de analizarlo.

Por eso "la eficiencia es la operación. La operación es aquel valor unitario de la causalidad que se conoce de acuerdo con la distribución afirmativa [el

\footnotetext{
39 L. POLO, Curso de teoría, IV, 322.

${ }^{40}$ L. POLO, La cuestión de la esencia extramental, 306.

${ }^{41}$ Ibidem, 305.

${ }^{42}$ Ibidem, 304.
} 
juicio]... La unión atañe exclusivamente a la operación, esto es, a la eficiencia entendida como conservación de la distinción causal”33. Comienzo incesante significa que el retraso no impide que el ser creado persista, pero sí implica que se unifique con el "no cesar" y el "no ser seguido", o sea, que la causa eficiente sea causa conjuntiva respecto de la causa material y la causa final, aun conservándose la diferencia entre estas dos.

Evidentemente esta conjunción es siempre inestable, no sólo porque no puede darse la identidad, sino porque la actividad no es la inercia; por eso, "la operación u ocurrencia, necesita concreción. Tal concreción no es la constancia, ni un valor que pertenezca de suyo a la conservación de la diferencia [entre causa material y causa final], sino un nuevo sentido causal, al que llamaré causa formal... sin la coimplicación de la causa formal la eficiencia no sería causa" ${ }^{\prime 4}$.

Quizás ahora se comprenda por qué no debe "suponerse" un sujeto del acto de ser (desde luego la esencia no lo es, puesto que es su analítica): "no es correcto entender que el sujeto del juicio tenga un equivalente extramental que sea, asimismo, sujeto, mientras el resto - el predicado y la cópula- marcan la consideración del sujeto en el juicio. La cuestión de la unión de sujeto y predicado no puede resolverse apelando a la formalidad del juicio, sino que es una cuestión extramental"45.

Si el acto de ser se describe como la realidad de la secuencia del antes y el después, siendo el "después" la ganancia pura pero inidéntica, es preciso que el antes se analice en co-principios, en causas no primeras sino concausales, que expliquen cómo puede un acto inidéntico ser no contradictorio; o, desde otro punto de vista, que un comienzo incensante no sea seguido (por la nada). Comentando la expresión forma dat esse, escribe Polo: "la causa formal no es única: el ser no es dado por una forma única, sino de acuerdo con la distribución, la diferencia, la determinación y la ordenación" ${ }^{36}$. Distribución y diferencia respecto de la causa material; determinación debida a la causa eficiente; y ordenación por la causa final.

Como síntesis de lo que se ha dicho pueden valer las siguientes palabras de Polo, en las que pone de manifiesto por qué la esencia es la analítica pasiva del acto: "las nociones analíticas de oposición [causa material], improrrogabilidad [causa final] y conjunción [causa eficiente] se han logrado a partir del

\footnotetext{
L. POLO, La cuestión de la esencia extramental, 306.

${ }^{44}$ Ibidem, 306-307.

${ }^{45}$ Ibidem, 296.

${ }^{46}$ L. POLO, Curso de teoría, IV, 324.
} 
significado trascendental del principio de no contradicción: la oposición atendiendo a lo incesante, la improrrogabilidad atendiendo al no ser seguido, y la conjunción incoativa atendiendo al comienzo. La noción de causa formal es la analítica en cuanto que tal, es decir, el modo de la donación del ser de acuerdo con una distinción interna" ${ }^{\text {"7 }}$, distinción en la que la inidentidad se compatibiliza con la no contradicción ${ }^{48}$.

Analítica y pasividad son, asimismo, inseparables, pues ninguna causa es causa de otra y ninguna causa sino en concausalidad con las demás: la coimplicación señala la pasividad, pero también la distinción entre las causas.

Advertir el acto y conocer la distinción real essentia-esse sin hacer de la esencia el sujeto del acto de ser, ni del acto la realidad de la esencia, puede resultar novedoso y extraño dentro de la tradición tomista, pero es el único modo de comprender que dicha distinción es real, sin ser una distinción entre dos res, o sea, que "la potencia es análisis pasivo porque no presupone el acto, es decir, porque el acto no cumple ninguna tarea en orden a ella. A la vez, el acto -creado- no tiene otro análisis que la potencia porque la persistencia no es una emanación ni una relación consigo, sino el enlace causal. Persistir no significa -para el acto- alcanzar un término, sino comenzar" ${ }^{\prime 4}$.

En resumen: "cabe hablar de actividad como enlace causal; cabe hablar de potencia o pasividad como carencia de referencia a sí mismo" ${ }^{\circ}$. O, lo que es lo mismo, como compatibilidad entre la Identidad y la no contradicción: "la persistencia, la no contradicción, sólo es vigente si a la vez es vigente la identidad, es decir, si demuestra la existencia de Dios" ${ }^{\text {51 }}$.

${ }^{47}$ Ibidem.

48 Aunque, como acabamos de leer, a la eficiencia "más directamente corresponde la ocurrencia esencial", Polo advierte reiteradamente que la causa formal es la analítica en cuanto tal, porque "la causa formal es el análisis puro de la persistencia, y, por tanto, una diferencia que se plasma, que se gradúa o desgrana y que se ordena según distintas concausalidades (existe una pluralidad de causas formales). Si la persistencia es el comienzo que ni cesa ni es seguido, su puro análisis es un dispensar o distribuir (sólo así cabe sostener que forma dat esse): no es análisis únicamente del comenzar, ni únicamente del no cesar, ni únicamente del no ser seguido. Sostener que la forma da el ser significa que es causa al servicio del ser (del persistir), y que sus servicios son múltiples, por la cual se adapta a los otros sentidos causales. Adaptación equivale a dispensación o distribución. Con otras palabras, la concausalidad de la causa formal evita el aislamiento de las otras causas del análisis extramental. Ese aislamiento sería contradictorio (el no ser seguido -la causa final- aislado, sería antecedido por la nada; el incesante no comenzar aislado, sería seguido por la nada)". L. POLO, Curso de teoría, IV, 501-502.

${ }^{49}$ L. POLO, El ser, 153.

${ }^{50}$ Ibidem.

51 L. POLO, Nominalismo, 251. 


\section{LA OCURRENCIA ESENCIAL}

Al tratar sobre la esencia extramental, Polo dice expresamente que no existe, en el sentido de que no es acto sino potencia, y la potencia se distingue realmente del acto de $\operatorname{ser}^{52}$. Que no "exista" no significa que sea irreal. Al contrario, la esencia extramental es real, pero, en lugar de existir, "ocurre". Éste es el término usado siempre por Polo aunque, quizás por su novedad, no siempre se entiende su significado.

¿Qué quiere decir "ocurrencia esencial" si no significa "existencia", es decir, si no es correcto afirmar que la esencia existe? Un primer texto nos permite acercarnos al tema; es el siguiente: "las causas físicas se distinguen realmente del acto de ser, de la persistencia. Son su análisis. Por otra parte, son extramentales o distintas de la actualidad objetiva y de las operaciones con que se conocen, puesto que se explicitan al pugnar con ellas la presencia mental. Sin embargo, estas distinciones no comportan que las causas físicas sean irreales, sino su carácter potencial y concausal" ${ }^{5_{3}}$.

También hemos visto que "potencia significa para el acto carencia de sí mismo. La consideración de la potencia como tal impide toda comparación de la potencia con el acto. Paralelamente, hay que desechar la idea de relación entre acto y potencia. Ahora bien, esto no quiere decir que potencia signifique nada ni que esté 'aislada' del acto... La potencia no tiene una positividad propia de que venga dotada por el acto. Su admisión no es un debilitamiento del acto, obligado a alguna tarea, sino precisamente la advertencia del acto. La admisión de la potencia no es determinación alguna, sino la persistencia activa" ${ }^{54}$. Estos textos, de entrada, parecen desconcertantes, sobre todo si se tiene en cuenta cómo se ha entendido la noción de "potencia" en la tradición aristotélica, para la cual, siguiendo fielmente a Aristóteles, se caracteriza por ser posterior al acto (salvo en el tiempo), por residir siempre en un acto como en su sujeto y por ordenarse al acto.

Ya se ve que estamos ante una concepción de la potencia distinta de la clásica, aunque, en realidad, no es que Polo intente "reinventarla", sino más bien corregir la interpretación clásica y hacerla acorde con la distinción real esse-essentia. La descripción del ente como "lo que es", en la que "lo" corres-

52 Por ejemplo: "a la esencia no corresponde ser en acto, sino pasividad analítica". L. POLO, El ser, 132.

53 L. POLO, Curso de teoría, IV, Eunsa, Pamplona, ${ }^{22004,} 636$.

${ }^{54}$ L. POLO, El ser, 152. 
ponde a la esencia, no es válida $\mathrm{o}$, al menos, debe ser corregida y matizada, porque, aunque se diga lo contrario, se acaba por hacer del ser el acto de la esencia (actus essentiae), por más que se insista en que no es el acto de la esencia sino del ente, siendo el ser y la esencia sus co-principios. Los primeros principios no pueden ser co-principios porque, en ese caso, no serían primeros; por tanto, si el acto de ser o persistencia es un primer principio, la esencia no puede serlo.

¿Qué quiere decir entonces "ocurrencia"? Polo lo expresa claramente así: "llamo ocurrir a la conjunción más alta, es decir, a la realidad de la concausalidad cuádruple en la que se incluyen por variación los cuatro sentidos causales. La concausalidad cuádruple ocurre sin más y nada más... En tanto que se distingue realmente del acto de ser, la persistencia, empleo la palabra ocurrencia. La ocurrencia equivale a la esencia extramental. La cuestión del 'es' se resuelve así: 'un universo es' equivale a un universo 'ocurre'; universo equivale, se reduce, a ocurrir. Reducirse realmente a ocurrir significa que al universo no se añade ningún sentido causal 'desde fuera"' ${ }^{55}$. Esta descripción de la "ocurrencia", con todo, requiere ser explicada, pues estamos ante un término nuevo que no puede reducirse a otros usados en la filosofía clásica.

Acto de ser y existencia son equivalentes; por eso la esencia, al distinguirse realmente del ser, no puede "ser". Y, sin embargo, es real, aunque potencial, ya que las causas predicamentales sólo son causas en concausalidad.

El carácter potencial y concausal no son distintos sino que la esencia es potencial por estar constituida de concausalidades. Es decir, no sólo se dan concausalidades o principios no primeros, sino que las causas sólo son causas en concausalidad: no son causas ni antes ni al margen de la "ocurrencia esencial" y, por lo mismo, no se pueden conocer al margen de dicha ocurrencia, o sea, de la "conjunción" de todas ellas. Su "realidad" viene dada por la ocurrencia esencial: "al distinguirse realmente del acto de ser están desprovistas de la capacidad de determinar desde sí un último significado suyo" ${ }^{\text {, }}$, porque no lo tienen. Por eso no sería acertado hablar de cada una de ellas por separado, como si "existiera" de ese modo, y luego se uniera a otras causas: "como los sentidos causales son el análisis del acto de ser, con ninguno de ellos se puede determinar su dependencia de éste. Por ejemplo, la causa eficiente no

${ }_{55}^{56}$ L. POLO, Curso de teoría, IV, 637-638.
L. POLO, Curso de teoría, IV, 637. 
depende del acto de ser de manera eficiente; tampoco el acto de ser es la causa final de la causa final, no las formas de las formas. Por ello ningún sentido causal está complicado en la tarea de llenar su propia ausencia. La ausencia de causas como 'situación previa' a las causas no significa nada: es un espejismo admitir una anterioridad extramental caracterizada como falta de causa. La pregunta: ¿qué hay antes de las causas? es un mero descontrol de la atención, una divagación. La pregunta: ¿qué causa física hay después de las causas físicas? no tiene sentido" ${ }^{\prime 7}$.

En otro lugar Polo se refiere, para explicar el sentido de la "ocurrencia esencial", al mundo de las Ideas de Platón, y a la doctrina aristotélica del hilemorfismo como solución al problema de la "locación" de las formas. Aunque Aristóteles hace de las formas "causas formales", pues están informando a la materia, tampoco esta respuesta es adecuada, porque las formas siguen siendo "formas", al margen de que puedan, en los cuerpos, informar a la materia; por eso Aristóteles habla de la existencia de "formas separadas" (de la materia), y las considera como existentes por $\mathrm{si}^{58}$.

La consideración de las causas por separado, o la distinción entre causas intrínsecas y extrínsecas respecto del ente, no resuelve el problema de la locación de las formas, ni explica la causalidad predicamental. Las formas sólo "ocurren" en concausalidad, y no sólo con la materia (teoría hilemórfica), sino en el universo, o sea, en la tetracausalidad. Además, el sentido de la forma varía según las distintas concausalidades, de modo que no es posible hablar de "forma" en un sentido único o unívoco. Sí es posible estudiarlas (y hablar) de ellas "por separado", porque no hay otro modo de hacerlo, pero a eso Polo le da normalmente el nombre, no de "abstracción" (la bicausalidades y la tricausalidades no se "abstraen" de la esencia), sino de reducción: "que las concausalidades sean múltiples comporta la variación de los sentidos causales, y que alguna causa sea irreal sólo significa que no entra en alguna concausalidad -por ejemplo, la causa eficiente en la bicausalidad hilemórfica-. A esto lo llamo reducción: por no ser reales sino en conjunción, la realidad de los sentidos causales se reduce a su variación" $"$.

De aquí se sigue que "la sustancia, el movimiento y la naturaleza son lo intracósmico; de ellos decimos que no llegan a distinguirse realmente del acto

57 Ibidem.

${ }^{58}$ Cfr. L. POLO, La cuestión de la esencia extramental, $275 \mathrm{~s}$.

59 L. POLO, Curso de teoría, IV, 637. 
de ser. En este sentido es más real el universo que la concausalidad hilemórfica, por más que sin ella no ocurra, y ella no aumente ni disminuya la ocurrencia -potencialidad de las causas físicas-. Reducirse realmente a ocurrir comporta que el análisis de la persistencia no es una duplicación o reconstrucción de ella"60.

Si el análisis lógico es incapaz de ser completo, pues se lleva a cabo mediante la generalización por negación, es decir, si no es posible "sintetizar" lo conocido uniendo las partes en las que se ha analizado ${ }^{61}$, tampoco el análisis real de la persistencia es una "duplicación o reconstrucción de ella". Por eso, para conocer la esencia extramental se requiere otra dimensión del abandono del límite mental distinta de la que advierte el acto de ser y admite la esencia. En concreto, el conocimiento, por explicitación, de la esencia del universo, "lleva consigo que el conocimiento del orden predicamental entero guarda implícito. Si el esse es principio, y lo es respecto de la esencia porque es acto respecto de ella, en el supuesto de que con el juicio se explicite el orden predicamental entero, todavía el juicio guarda implícito, y ese implícito será el fundamento. El fundamento es ya una manera de conocer el esse" ${ }^{2}$.

La esencia es potencial también porque nunca cumple plenamente el orden, o sea, porque -como la persistencia, pero de otro modo- tampoco culmina sino que depende de la Identidad. Para el acto de ser culminar sería ser idéntico, pero la identidad sólo puede ser originaria; para la esencia, por su parte, no culminar es no cumplir nunca el orden, no estar nunca "acabada"; por eso "comporta una potencialidad que se distingue realmente del acto de ser. Y así podemos decir que el acto de ser es el acto de ser del universo, sí; pero en tanto que éste es realmente distinto de él por ser potencial” ${ }^{63}$. Además, "causa no significa más que sentido causal; precisamente por eso no puede significar cosa, y tampoco sustancia...: las causas son causas entre sí. Eso quiere decir que ninguna de ellas es suficientemente causa, que son causas tales que unas se ayudan a las otras, o que ninguna de ellas agota el sentido de la causalidad" ${ }^{64}$. Concausalidad, por tanto, equivale a pasividad y a potencialidad. En cambio, la persistencia no es pasiva ni potencial; al contrario, se equipara al mo-

\footnotetext{
${ }^{60}$ Ibidem, 638-639.

${ }^{61}$ Ibidem, 92, nt. 1.

62 L. POLO, El conocimiento del universo físico, Eunsa, Pamplona, 2008, 264.

${ }^{63}$ L. POLO, El universo físico, 424-425.

${ }^{64}$ Ibidem, 245.
} 
vimiento $\mathrm{y}$, aunque no sea seguida, depende de la Identidad, y por eso no puede decirse que es potencial.

La esencia, pues, no es el "sujeto" de la forma, o de la materia, o de aquello sobre lo que actúa la causa eficiente, o lo que está finalizado para llegar a perfeccionarse. El sentido de cada una de las causas ha de entenderse de otro modo porque, propiamente, no "existen" causas sino que ocurren concausalidades. Por eso también, "para entender la esencia extramental como potencia realmente distinta del acto de ser es menester ampliar y matizar la noción de potencia, que en el aristotelismo se restringe a la materia o, como distinta del acto enteléquico, a lo actuable por un acto imperfecto, o no actual: el movimiento (entendido como cambio...). La propuesta de ampliación de la noción de potencia es imprescindible para sentar con rigor la distinción essentia-esse"

Por otra parte, el acto de ser no es temporal; en cambio su análisis da lugar al tiempo físico: un acto creado (inidéntico) y no temporal, tiene que expandirse temporalmente a través de causas no primeras; la esencia, por eso, "depende" del primer principio, es su análisis pasivo, o sea, potencial: "el acto de ser que persiste, en atención a su análisis (a la consideración de la potencialidad que le corresponde a un acto de ser no contradictorio, pero no idéntico), admite distinción real con la esencia" ${ }^{66}$. O, como ya hemos leído, "el esse es principio, y lo es respecto de la esencia porque es acto respecto de ella" ${ }^{67}$.

En resumen, la persistencia no es acto potencial sino que se distingue realmente de la esencia, la cual es potencia respecto del acto de ser. Además, el ser no es el acto de la esencia-que no deja nunca de ser potencial-, ni tiene como cometido llevarla a plenitud o actualizarla. El ser es la existencia, o mejor, equivale a existencia, mientras que la esencia, en cambio, ocurre, porque es su análisis pasivo y nunca deja de ser potencial. Lo que sí debe afirmarse es que la esencia "depende" de la persistencia porque ésta es acto respecto de ella, es decir, porque al acto de ser creado acompaña, por ser inidéntico, la esencia extramental. Por eso, la esencia es el "beneficio" del principio de causalidad respecto del principio de no contradicción.

${ }^{65}$ L. POLO, Curso de teoría, IV, 601, nt. 83.

${ }^{66}$ C. E. VANNEY, Principios reales y conocimiento matemático. La propuesta epistemológica de Leonardo Polo, Eunsa, Pamplona, 2008, 357.

${ }^{67}$ L. POLO, El universo físico, 264. 


\section{LA REALIDAD DE LA ESENCIA EXTRAMENTAL Y SU DEPENDENCIA}

\section{DEL ACTO DE SER}

Hablar de "ocurrencia" esencial, a pesar de lo dicho hasta ahora, puede seguir siendo confuso, en el sentido de que no se ha respondido a la pregunta sobre la "existencia" de la esencia extramental. Sin embargo, la respuesta está implícita en lo ya visto. El problema para comprender a Polo reside aquí en el modo de expresarse la filosofía tradicional, o sea, la que Polo llama "metafísica prematura", para la cual el acto de ser del universo no es único sino que cada res posee su propio acto de ser.

Hay que tener en cuenta que "la metafísica prematura es inevitable y encuentra su justificación en la imposibilidad de que a las operaciones racionales no correspondan objetos. Sin embargo, todo objeto es intencional (axioma lateral F), por lo cual la cuestión de los objetos de las operaciones racionales obliga a averiguar la referencia intencional que les es propia. La pretensión de una metafísica intencional -que verse sobre los primeros principios- ha de descartarse si se admite una axiomática metafísica: la axiomática metafísica difiere de la axiomática de las operaciones cognoscitivas humanas y, por tanto, no es objetiva" ${ }^{\prime 8}$. Dicho de otro modo: si los primeros principios son sólo principios lógicos o, como mucho, leyes que debe cumplir la realidad para no ser contradictoria, entonces no es posible evitar la "metafísica prematura", que lleva a asignar un acto de ser a la sustancia, entendida como lo propiamente ente, es decir, como "aquello que es".

El planteamiento poliano es muy distinto, entre otras cosas porque esa metafísica prematura se enfrenta con aporías que no puede resolver. Un ejemplo lo mostrará suficientemente: "nótese que si el sujeto y el predicado son supuestos, es decir, objetos pensados, unidos por la cópula verbal, la proposición no puede ser un objeto pensado (ni siquiera como se ha dicho que lo son las compensaciones racionales), pues objetivamente sólo se conoce lo uno o lo mismo... Pero es claro que el sujeto y el predicado no son lo mismo, sino objetos heterogéneos. Esta observación es indicio de que, en rigor, el sujeto y el predicado unidos por la cópula no son objetos pensados, sino objetos inferiores a éstos..." ${ }^{\prime 69}$. Aquí Polo está señalando un problema grave de la doctrina tradicional acerca del juicio, según la cuál éste consiste en la unión de dos con-

68 L. POLO, Curso de teoría, IV, 539.

69 L. POLO, Curso de teoría, IV, 577, nt. 58. 
ceptos mediante la cópula verbal. Polo, por su parte, niega esta doctrina, pero no porque no coincida con la suya, sino porque es incongruente, porque contradice lo que la propia metafísica prematura afirma.

En la filosofía tradicional aristotélica se entrevió el problema, pero no se llegó a una solución satisfactoria, precisamente porque al ser "prematura", la metafísica "suponía" que ya se había conocido la realidad. "La doctrina aristotélica del juicio considera que la dimensión lógica es inherente a la afirmación. Según esto, afirmar equivale a sostener que uno o más predicados pertenecen a un sujeto y se dice de él mediante la cópula. Paralelamente, al entender el juicio como proposición, los aristotélicos admiten que la complexión (simploké) lógica no es estrictamente real. En la realidad no hay sujetos y predicados, aunque esa complexión indica una composición real que, por ser lógica, se ignora, a pesar de que la predicación se corresponde con ella (es el único modo de conocerla). De modo similar a lo que se dice de los universales, habría que sostener que la predicación tiene fundamento in re" ${ }^{\text {"70 }}$. El juicio, en el que -se dice- se conoce el acto de ser, en realidad no conoce ni la unión del sujeto y el predicado; lo más que puede decirse es que dicha unión se da, pero no se sabe cómo ni por qué.

La propuesta de Polo, a partir del abandono del límite mental, es más coherente, porque evita de raíz estos inconvenientes, dándoles una solución apropiada. "Sin la inhesión los accidentes se soltarían; serían ampliaciones dispersas, ilimitadas o extravagantes. La naturaleza, la concausalidad equilibrada por inhesión, es explícita en el juicio. El esquema de las categorías, lo afirmado, es la explicitación de la diferencia que el objeto abstracto guarda implícito; explicitar no es predicar o añadir otro al abstracto, sino lo vasto expandido, ampliado hacia dentro al 'despresenciarlo', es decir, al pugnar la presencia con él. En tanto que articulado en presencia, el abstracto es un objeto conmensurado, y no ocurre físicamente; despresenciado, ocurre, y ello quiere decir que no es actual, sino potencial" "11. Es decir, las sustancias y las naturalezas son concausalidades intracósmicas, a las que, por tanto, no cabe atribuir el acto de ser, ya que éste se distingue realmente de la esencia tetracausal, no de las concausalidades inferiores. Por eso, juzgar es "expandir" el abstracto, explicitar las diferencias que guarda implícitas, no predicar propiedades o accidentes de un "supuesto" sujeto existente; "por ello se ha señalado repetidamente que

${ }^{70}$ L. POLO, Curso de teoría, IV, 577.

${ }^{71}$ L. POLO, Curso de teoría, IV, 618. 
la concausalidad doble o triple con causa eficiente extrínseca es una concausalidad restringida: no es la esencia, el universo. Ahora bien, esta restricción es apropiable por la estructura de sujeto y predicado, es decir, por la compensación judicativa"'?2.

Desde luego la metafísica prematura parece a primera vista más acorde con el sentido común, con lo que solemos pensar y juzgar; es así, puesto que es la metafísica posible si no se abandona el límite mental. Pero, como se ha visto, da lugar a problemas que no tienen solución y a contradicciones. Quizás lo más extraño de la posición de Polo es que siempre falta el "sujeto", sin el cual parece que no sólo no se puede pensar sino que tampoco podría existir el juicio. La respuesta a esta cuestión es la siguiente: Polo no admite el "sujeto", pero sí el "individuo", aunque entendido de un modo distinto al de la metafísica clásica: "el individuo es la complejidad de las inhesiones descritas. No es ninguna de las categorías consideradas por separado (ni siquiera la sustancia), pero tampoco es una cuestión inefable, que se escape de la explicitación judicativa, sino la potencia de causa y la naturaleza. Las inhesiones no son posibles sin la tricausalidad en que la causa eficiente es intrínseca; paralelamente, un individuo físico es un analogado"

Por usar un ejemplo que emplea Polo, una vaca no es un ser o un ente, sino un "individuo físico", que sólo puede existir en el universo ${ }^{74}$. Por tanto, las sustancias y las naturalezas no "son" sino que son intracósmicas: no se distinguen realmente del acto de ser sino que son concausalidades que ocurren en el universo.

Ni siquiera el universo entero -la tetracausalidad- “es”, porque la causa final "orla" la tricausalidad, es decir, porque el orden del universo (causa final) lo cumplen las restantes causas, ordenadas por ella, pero no ella misma. Por eso, en los juicios, si no se abandona el límite mental, el "es" tiene valor lógico y muy escaso valor real: indica inhesión de las categorías, o sea, concausa-

2 L. POLO, Curso de teoría, IV, 585.

L. POLO, Curso de teoría, IV, 600.

74 "Decir que una vaca es una esencia distinta del acto de ser, es impropio. Lo que es distinto realmente del acto de ser es el universo. La vaca es intracósmica; es una tricausalidad ordenada: un ser vivo, una realidad viva, que por ser corpórea es tricausal, y que se explicita en tanto que cumple la unidad de orden, según lo que es intracósmica... Por tanto, no se puede decir que los actos de ser se correspondan con las sustancias, ni siquiera si son naturalezas. De lo contrario resultaría una plurificación del acto de ser verdaderamente notable: tantas vacas, tantos actos de ser; tantos perros, tantos actos de ser. No; el acto de ser del universo es únicamente el acto de ser del universo". L. POLO, El universo físico, 423 y 424. 
lidades. "Las concausalidades doble y triple intrínseco son explícitos cuyo ocurrir no es exterior al universo... Las compensaciones son detenciones en la explicitación de la principialidad. La detención judicativa son los predicamentos unidos por la débil complexión que es la proposición. Juicio y proposición suelen confundirse" 75 .

Terminemos este apartado con un texto más extenso en el que Polo se muestra aún más explícito y resuelve, si es que aún no se ha hecho, posibles dudas acerca de la "existencia" de la esencia extramental: "en la expresión 'un universo es', 'es' no es un predicado verbal porque 'un universo' no es sujeto. Por tanto, se ha de distinguir del sentido predicativo del 'es', el cual es lógico: el 'es' de la mentada expresión no tiene ese carácter. De otro lado, su alusión a la realidad es obvia. Sin embargo, su significado estricto es problemático: ¿qué quiere decir 'es' sin más? Si no se dice de un sujeto, ¿de qué se dice, o no se dice de nada? $\mathrm{O}$ bien: ¿en qué sentido se dice del universo, no siendo el universo sujeto alguno? En definitiva, ¿por qué se dice 'es'?... Ahora bien, si 'es' no expresa la realidad del esse, parece invitar a proseguir en la averiguación sobre la realidad: la averiguación sobre lo real no acaba en 'es"'76.

La esencia -la ocurrencia esencial- depende de la persistencia, que es el acto de ser; por tanto, ella no "es" la existencia sino que "ocurre" y la persistencia es el fundamento: funda la esencia, la cual no está desasistida o en tiera de nadie -como las Ideas de Platón-. En conclusión, "el fundamento no es explícito en el juicio, el cual guarda implícito el sentido no proposicional del 'es' (su manifestación habitual permite ejercer la tercera operación racional). Por eso, lo afirmado no es una totalidad unívoca ni autosuficiente: ello sería algo así como una petición de principio..., pues ya he dicho que en el juicio el fundamento no es explícito. Tampoco cabe proseguir la fase judicativa hacia la afirmación absoluta. Lo afirmado es la diversidad de sentidos causales concurrentes en concausalidad cuádruple o completa" "'7.

De este modo puede sentarse que la esencia se distingue realmente del acto de ser, siendo éste el fundamento de la esencia. No hay, por tanto, dos actos de ser, uno la persistencia y otro el acto de ser de la esencia. Tampoco el acto de ser del universo tiene que hacer ser a la esencia (no es actus essentiae), sino que, por ser creada, de la persistencia depende la esencia extramental.

\footnotetext{
${ }^{75}$ L. POLO, Curso de teoría, IV, 585.

${ }^{76}$ L. POLO, Curso de teoría, IV, 578, nt. 60.

${ }^{77}$ L. POLO, Curso de teoría, IV, 602.
} 
Como ya se ha visto, ser creado equivale a comenzar, y el comienzo implica un "retraso", una potencialidad, que no es exclusiva de la causa material sino que, por así decir, "condiciona" al acto de ser hasta el punto de que -por no ser idéntico- puede ser analizado en co-principios no primeros por ser concausales y, por consiguiente, potenciales: "la pluralización es justamente la pluralización del primer principio; y esta pluralización, congruentemente, tiene que ser según causas, es decir, según distintos sentidos causales, que a su vez son ad invicem: no están separados; ninguno de ellos es suficiente aislado; aislado no puede ocurrir, no puede ser real" ${ }^{\text {78 }}$.

Ahora es más accesible comprender por qué sin la causalidad trascendental no puede darse la predicamental y por qué "el beneficio del principio de causalidad -sin macla- para la persistencia es la analítica causal". ¿Por qué "beneficio" si la esencia, en cuanto realmente distinta del acto de ser, se debe a que éste es creado? La respuesta es como sigue: "por ser la persistencia creada, también lo es su análisis. La causa final es un designio divino y la causa material un favor. Por su parte, las causas formales son decretos y las causas eficientes ejecuciones obedientes. Esta terminología sirve para insinuar una dimensión de la providencia de Dios: su consentimiento respetuoso, su lealtad, su salir por los fueros de lo creado al gobernarlo. Nótese que la persistencia es equivalente al primer principio de no contradicción: si Dios no lo respetara, el acto de ser del universo ad nibilum redigeretur" ${ }^{\text {"9 }}$.

\section{La PERSistenCIA COMO "CAUSA CAUSADA"}

El principio de causalidad establece la vigencia del principio de identidad y el de no contradicción y, según la terminología usada por Polo, permite advertir la persistencia como "causa causada". Esta expresión ha causado algunos quebraderos de cabeza a sus discípulos porque, dentro de la filosofía poliana, parece una contradicción.

Que la persistencia sea creada como "causa" parece normal si se tiene en cuenta que no puede ser "efecto" del acto creador de Dios, ya que Dios no es Causa Primera -la creación active sumpta es Dios- y, además, el efecto debe estar precontenido en la causa, salvo que, en algún sentido o aspecto no sea efecto; si el efecto tiene consistencia propia, aquello que le hace no depender de

\footnotetext{
78 L. POLO, El universo físico, 425.

79 L. POLO, Curso de teoría, IV, 605, nt. 90.
} 
la causa no lo ha recibido y, en ese aspecto no es efecto sino, si acaso, "producto" de una acción sobre algo preexistente.

Dios crea la "causa"; hasta aquí la expresión de Polo es admisible sin reparos. Pero, ¿por qué añade que es "causada"? ¿Causada" quiere decir creada? Evidentemente no si crear significa causar, porque se opondría a todo lo dicho por Polo no una, sino muchas veces. ¿Qué quiere decir entonces?

Leyendo atentamente sus obras aparece, en primer lugar, que esta expresión se encuentra ya en $E l s e r$, y que vuelve a aparecer más de treinta años después en Nominalismo, idealismo y realismo, o sea, que Polo la sigue considerando válida.

Si "causa causada" no significa "causa creada" en el sentido usual de esta expresión, ¿¿cuál es su sentido? Una propuesta, congruente con la terminología poliana es la siguiente: la persistencia es causa no causada sino creada, pero Dios en cuanto Dios no es creador. Por eso, "causa causada" es el modo de expresar que es una causa creada una vez que ha quedado claro que no es causada por Dios, es decir, que la causalidad es su ser. "La noción de causado no tiene sentido pasivo porque equivale a la persistencia del comienzo. Sólo así ser causado significa ser hecho, ser creado" ${ }^{\circ 0}$.

Otro modo de entender la expresión "causa causada", quizás más congruente con los textos de Polo y sin oponerse a lo dicho hasta ahora, sería el siguiente: la persistencia se describe también como "el carácter existencial del movimiento; el carácter existencial del movimiento es la actividad no contradictoria. Y la actividad no contradictoria es la criatura causal" ${ }^{11}$; o sea, persistir es actividad (no contradictoria) incensante y, en este sentido, causada. No quiere decirse que la criatura sea causa de su propia persistencia -algo así como causa sui o causa de su ser no contradictorio-, sino que es creada como persistente y, por tanto, no sólo como causa, sino como causa persistente e incesante ${ }^{82}$. Así puede entenderse el siguiente texto: "si persistir equivale a depender, depender no significa depender de otro. La eliminación de la idea de otro se entiende así: en tanto se habla de persistencia en cuanto se habla de dependencia; pero también al revés. Depender no es depender de otro porque no es depen-

${ }^{80}$ L. POLO, El ser, 246.

${ }^{81}$ L. POLO, El ser, 72.

${ }^{82}$ Este sentido de la causalidad es explícito en el siguiente texto: "la causalidad real es cierta consecutividad temporal real. Si de que algo sea no se sigue que siga siendo, entonces de que algo sea no se sigue que sea causa". L. POLO, Estudios de filosofía moderna y contemporánea, Obras Completas, XXIV, Eunsa, Pamplona, 2015, 57. 
der-algo: la plenitud de la persistencia es la dependencia; la omisión de la persistencia sería la omisión de la dependencia. De manera que la noción de dependencia no nos remite a lo más perfecto que lo que depende, sino que nos remite, en términos de persistencia, a su propio sentido de perfección. Tal perfección es la existencia creada" ${ }^{83}$.

Otro texto quizás resulte aún más explícito: "la criatura se dice respectiva a la identidad en cuanto ella misma es causa, en cuanto la no contradicción persiste, no en cuanto sea causa de un modo deficiente que en Dios encuentra la perfección... La causa causada es respectiva a la originaria superioridad de la que depende, en su mismo carácter causal y no contradictorio, como persistencia" ${ }^{\$ 4}$.

El conocimiento objetivo no puede conocer la persistencia porque la "detiene" en el presente; pero el carácter existencial del movimiento, cuando el movimiento no se entiende como "cambio" sino como persistencia, implica no detenerse en su advertencia, sobre todo porque la advertencia no culmina, no llega nunca a objetivarse: la persistencia no cesa ni es seguida y, por eso, puede decirse "causada". Pero no "causada" por Dios, sino que "causada" es una descripción de la "causa" como persistente. Polo lo expresa así: "la proposición 'la dependencia es la persistencia', equivale al sentido trascendental de la noción de dependencia; y la proposición: 'la persistencia es dependencia', es la advertencia de que la persistencia no suspende la identidad originaria" ${ }^{85}$. Dicho de otro modo, siempre impreciso: persistir es causar... el persistir, pero no como causa sui sino como dependencia de la Identidad.

Lo que debe quedar siempre a salvo es que "la persistencia no depende de sí misma" y, por otro lado, que "reducir a Dios a la consideración paradigmática de la causalidad hace imposible la consideración creatural de la causalidad... La causa causada es respectiva a la originaria superioridad de la que depende, en su mismo carácter causal y no contradictorio, como persistencia" ${ }^{86}$. Que la "causa" cause su persistir no significa que es su propia causa, sino que, en cuanto causa, depende, no culmina.

De todos modos, la expresión, tomada literalmente y según el sentido tradicional de la causalidad, indica que la persistencia es causada y, por consiguien-

${ }^{83}$ L. POLO, El ser, 80. "La creación no es causa en Dios o como Dios, sino en la criatura, con tal de que se excluya que la criatura sea primera según la macla de identidad y no contradicción (según esa macla no cabe criatura)". L. POLO, Nominalismo, 242.

${ }^{84}$ L. POLO, El ser, 81.

${ }^{85}$ L. POLO, El ser, 81.

${ }^{86}$ L. POLO, El ser, 81. 
te, que Dios es su Causa. Sin embargo, una vez que ha quedado claro que Dios no es la Causa Primera, la fórmula puede entenderse correctamente: el ser del universo es causa pero no es efecto porque no está precontenido en ninguna causa; su "causalidad" -o sea, su ser- depende del Origen, no como causado sino como creado o donado. "Causa causada" es la expresión de que el persistir es una causa creada, en la que la causalidad es su ser y este ser admite análisis real según concausalidades, que es como se distingue realmente de la nada. La criatura es causa porque comienza, y es causada porque no culmina.

Si Polo hubiera escrito que "la criatura es causa creada", no se hubiera planteado ninguna duda, pero la expresión "criatura creada" es una tautología -la criatura es criatura-, o bien daría a entender, quizás, que, una vez creada, goza de autosuficiencia -que es consistente-, o sea, que no depende del Creador. Por eso, y teniendo en cuenta que el filósofo ha de luchar continuamente con el lenguaje, el cual depende del pensar objetivo, "causa causada" puede entenderse sin confusión, aunque sea, desde el punto de vista lingüístico, una expresión que se presta a ser malinterpretada. Quizás aquí valga la expresión clásica según la cual sapientis enim est non curare de nominibus ${ }^{87}$.

De todos modos, lo que Polo deja claro es que "en tanto que el causar comporta el no ser ultimado, es la demostración del Incausado... Según esto, la causa se asimila al principio de no contradicción en tanto que distinto de la identidad, y, por eso, distinto realmente de su esencia"s8, ya que, como se ha dicho, la realidad de la secuencia del antes y el después se sintetiza en la expresión "causa causada".

${ }^{87}$ SANTO TOMÁS DE AQUINO, In II Sent., lect. 3, q. 1, a. 1. Además ya santo Tomás advertía que la creación no es completamente descifrable por la filosofía, y Polo comparte este punto de vista: cfr. Nominalismo, 255 , nt. 42.

${ }^{88}$ L. POLO, Nominalismo, 259. 